\title{
Role of Social Media in Earthquake: A Systematic Review
}

\author{
Mohammadreza Amiresmaili1 ${ }^{1}$, Farzaneh Zolala², Mahmood Nekoei-Moghadam³, Siavash Salavatian ${ }^{4}$, \\ Mohammadreza Chashmyazdan ${ }^{5}$, Ahmad Soltani ${ }^{6,7}$ and Jaber Savabi ${ }^{8, *}$ \\ $1 \mathrm{PhD}$, Health in Disasters and Emergencies Research Center, Institute for Futures Studies in Health, Kerman University of Medical Sciences, Kerman, Iran \\ $2 \mathrm{PhD}$, Social Determinants of Health Research Center, Institute for Futures Studies in Health, Kerman University of Medical Sciences, Kerman, Iran \\ $3 \mathrm{PhD}$, Health in Disasters and Emergencies Research Center, Institute for Futures Studies in Health, Kerman University of Medical Sciences, Kerman, Iran \\ ${ }^{4} \mathrm{PhD}$, Communication and Media Faculty, IRIB University, Tehran, Iran \\ 5 PhD Candidate, Department of Medical Library and Information Science, Kerman University of Medical Sciences, Kerman, Iran \\ $6 \mathrm{PhD}$, Iran-Helal Institute of Applied-Science and Technology, Red Crescent Society of the Islamic Republic of Iran, Tehran, Iran \\ ${ }^{7}$ Research Center for Health Management in Mass Gathering, Red Crescent Society of the Islamic Republic of Iran, Tehran, Iran \\ $8 \mathrm{PhD}$ Candidate, Health in Disasters and Emergencies Research Center, Institute for Futures Studies in Health, Kerman University of Medical Sciences, \\ Kerman, Iran
}

* Corresponding author: Jaber Savabi, Health in Disasters and Emergencies Research Center, Institute for Futures Studies in Health, Kerman University of Medical Sciences, Kerman, Iran. Tel: 03431325221; Email: J.savabi@kmu.ac.ir

Received 2021 February 03; Revised 2021 February 25; Accepted 2021 April 15.

\begin{abstract}
Context: Social networks can perform a peculiar role in people's communication in the case of crisis and disaster. These media are interactive, digital, or mobile-based tools. Accordingly, the present study aimed to assess the role of social media in earthquakes.

Evidence Acquisition: In this current systematic review, a query was conducted on such databases as Embase, Web of Science, Scopus, and Cochrane for articles in English language, based on the required criteria from 2000 to 2019 regarding the role of social media in disaster. As a result, 13,924 studies were retrieved, among which 3,963 were deleted due to duplication. Finally, among 244 selected articles, 19 full-text articles were analyzed.

Results: In the present research, 19 studies were thoroughly reviewed. The findings were assigned to four main categories (identification, notification, requests, as well as storage and retrieval of information) with 12 sub-topics. Most of the main topics and subsets were as follows: medical and food needs, information about the accident, as well as medical and relief services, efforts to save lives, the amount of damage, problems and limitations, post-crisis measures, such as keeping calm, reducing anxiety, avoiding highrisk areas, asking for financial assistance, as well as using the information to provide relief and map the affected areas and evacuation centers.

Conclusion: Considering the behavior of people in different geographical locations in the earthquake crisis, it seems that the case study of how to use social media in disaster management carries profound implications for modeling and localizing the cases in related disaster management institutions of many different countries, such as Iran.
\end{abstract}

Keywords: Disasters, Earthquakes, Social media, Systematic review

\section{Context}

Nowadays, information performs a peculiar role in effective crisis management, and social media is one of the new sources of information for disaster relief organizations, enhancing situational awareness and mutual communication (1). Moreover, these media can contribute greatly to people's communication in times of crisis and disaster (2). Since these media are interactive digital or mobilebased tools, they can allow users to produce new content, access information, and influence available content (3). Social media can be used either as a communicative or information dissemination tool during disasters in crisis management (4). The effective use of social media in both ways may reduce the effects of disaster (5). Therefore, effective use of social media in crisis management leads to increased acceptance of management strategies and improvement in disaster management programs (6).

However, serious obstacles are posed to the use of social media in the dissemination of important information. In many cases, the high volume of information may not be relevant or useful (7) since it is not entirely relevant to the location of the incident or does not address the involved people $(8,9)$. Lack of communication or poor communication among respondents can also increase the burden of problems rather than facilitating them (10). In addition, social factors, such as gender, ethnicity, income, and geographic location can influence easy access to social media and other online resources (11-13). The reliability of information created or shared through social media during disasters can also be questioned (10) since information dissemination does not require authentication, and most people do not publish the sources of original data $(9,14,15)$.

Although people still rely heavily on mainstream media, such as television and radio, to obtain information about the crisis, their trust in social media has gradually increased (16). For instance, during the Sandy Storm in 2012, about 800,000 photos were published with the hashtag \#Sandy on Instagram. These photographs also showed their geographical location (1). In the 2015 Haiti earthquake, various digital crisis management tools 
were used which released around 1,500 reports showing the affected areas and the number of victims on the map, and they were widely used by US Red Cross and the Haitian government in their operations (17). Therefore, these media play an important role in crisis control.

There has been a wealth of research on the role of social media in earthquakes in recent years, and the number of these studies has been on a rise. The results of the present study can be applied by managers in crisis management. As a systematic review, the current research aimed to analyze the effective role of social networks in earthquakes.

\section{Evidence Acquisition}

\subsection{Search Strategy}

This systematic review method was conducted on the related research papers regarding the role of social media in crisis and disaster. To this end, a query was conducted on reputable databases, including Embase, Web of Science, Scopus, and Cochrane within 2019-2000 to retrieve articles on the role of social media in earthquakes using the keywords of natural disaster, earthquake, and social media and Boolean Operators ( AND/ OR). Some Examples of search performed on the Web of Science database were in the following states:

TS= (C"Natural disaster" OR "Natural disasters" OR earthquakes OR Earthquake OR Disaster) AND ("Social media" OR "social network" OR "social networking" OR "social software" OR "social medium" OR "social web" OR "web 2.0" OR "web2" OR microblog OR weblog OR blog OR Blogging OR Facebook OR YouTube OR Twitter OR tweet OR Internet OR WeChat OR Skype OR WhatsApp OR Viber OR Messenger OR Instagram OR Telegram)).

\subsection{Assessment of the Recovered Documents}

Duplicate results were removed after searching the target databases using Endnote software (version 8). Following that, the researcher again manually reviewed the recovered documents to ensure the removal of all the duplicates. After removing the overlaps, the title and abstract of all retrieved documents were initially reviewed by the researcher. In the second stage, after retrieving the file, the texts of the available articles were reviewed by the researcher.

The inclusion criteria entailed: 1) articles published in English, 2) research papers, conferences, reviews, reports, and commentaries, 3) articles that were thematically focused on the role of social networks in earthquakes, 4) articles released from 2019 to the end of August 2000. On the other hand, the exclusion criteria were as follows: 1) articles published in languages other than English, 2) letter to the editors, editorial articles, 3) articles that were not related to the question and purpose of the research, 4) articles that focused on computational methods for simulation.

The quality of the selected articles was assessed with Strobe and Coreq checklists

\subsection{Data extraction}

After the final selection of articles, information was extracted from the full text articles. This information was divided into two separate sections. The first part of the bibliographic information of the articles included the title of the article, the year of publication, the first author, and the title of the journal. In the second part, based on the objectives of the research, the related topic results mentioned in the articles were extracted.

\subsection{Data analysis}

Finally, each selected study was carefully read to identify the key concepts and themes. After the completion of the data extraction table, the researcher shared the extracted concepts with other members of the research team, and finally, an agreement was reached among all the members.

\section{Results}

A total of 13,924 studies were retrieved, among which 3,963 cases were deleted due to duplication. Finally, among 244 selected articles, 19 full-text papers were analyzed (Figure 1). Among the analyzed papers, 11 original research papers, 6 conference ones, 1 commentary based, and 1 short report paper were published, respectively. Regarding social media, 16 and 2 articles used Twitter and WhatsApp to help in the event of an earthquake. The highest use of social media was in the first hours after the earthquake and up to the first three days. On the others hand, the lowest number of messages was on the third day. The most and least studies were in $2017(n=5)$ and 2013-2015 $(n=0)$. The majority of studies were conducted in Nepal with seven studies, while the least was performed in Haiti, the east coast of the United States, the southern island of New Zealand, Mexico, China, and the Philippines, respectively. The main characteristics of these studies are presented in Table 1.

\subsection{Role of social media in earthquakes}

A number of 19 studies were thoroughly reviewed. The findings were assigned to four main topics, including identification, notification, requests, as well as information storage and retrieval in 12 sub-topics (Table 2). Identification refers to the extraction of information related to identifying and rescuing people from social media after an earthquake. This main category contains two main themes. The findings demonstrated that efforts to save lives, as well as medical and nutritional needs, are some of the factors shared on social media. 


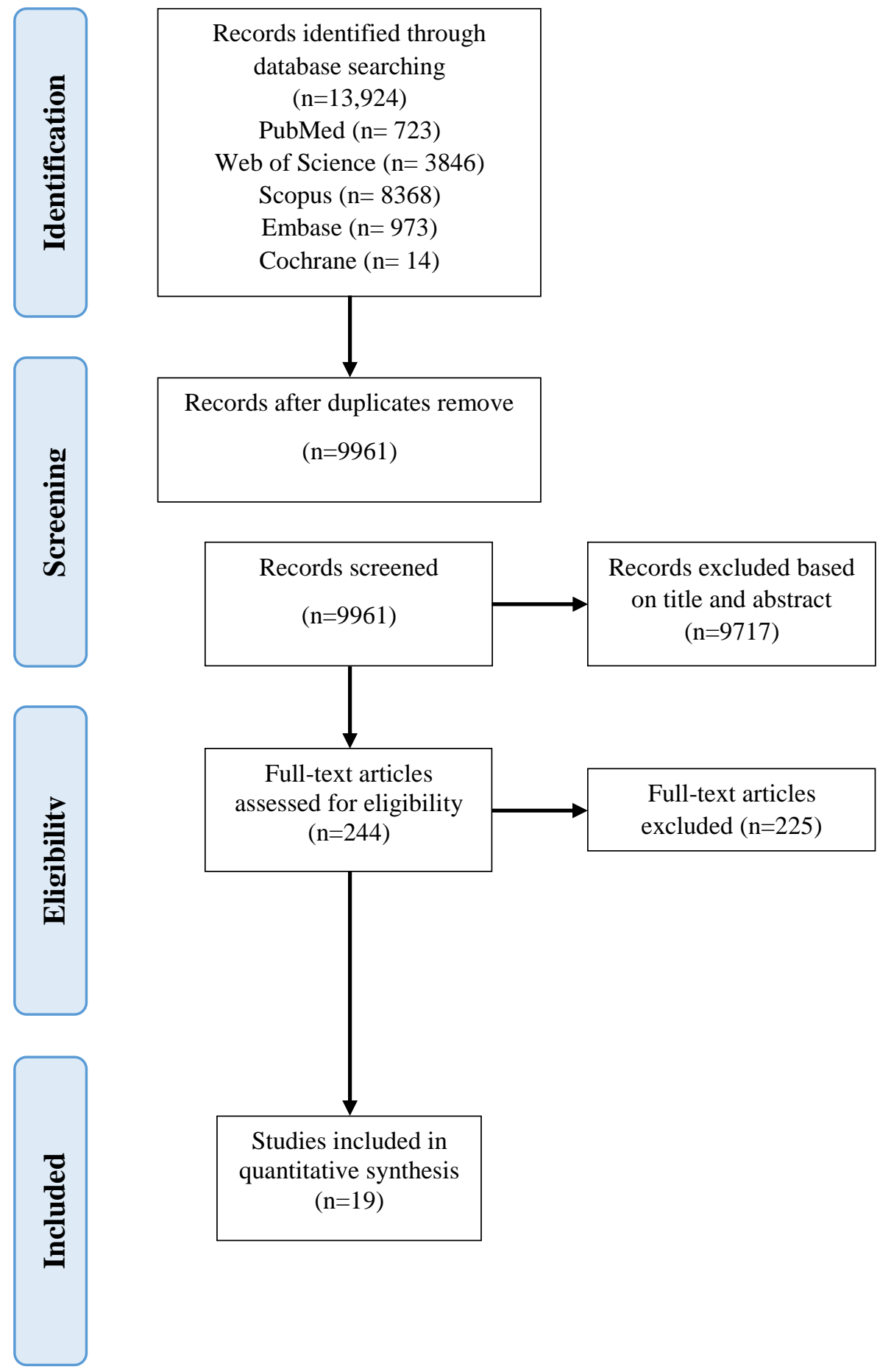

Figure 1. Levels of search and selection of articles (flow diagram)

\begin{tabular}{lcccccc}
\hline \multicolumn{2}{l}{ Table 1. Summary of features of articles included in the study } & & & & \\
\hline Row & Title & Author & $\begin{array}{c}\text { Research } \\
\text { Type }\end{array}$ & $\begin{array}{c}\text { Publication } \\
\text { Date }\end{array}$ & $\begin{array}{c}\text { Type of } \\
\text { Accident }\end{array}$ & $\begin{array}{c}\text { Geographical } \\
\text { Region }\end{array}$ \\
\hline $\mathbf{1}$ & $\begin{array}{c}\text { A Citizen-Sensing-Based Digital Service } \\
\text { for the Analysis of On-Site Post- } \\
\text { Earthquake Messages }\end{array}$ & $\begin{array}{c}\text { Paolino Di } \\
\text { Felice }\end{array}$ & Original & 2019 & Earthquake & Italy \\
$\mathbf{2}$ & $\begin{array}{c}\text { Management of Natural Disasters } \\
\text { Based on Twitter Analytics. 2017 } \\
\text { Mexico Earthquake }\end{array}$ & Mexico & Original & 2019 & Earthquake & Mexico \\
\hline
\end{tabular}




\begin{tabular}{|c|c|c|c|c|c|c|}
\hline \multicolumn{7}{|c|}{ Table 1. Continued } \\
\hline 3 & $\begin{array}{c}\text { An Analysis of Tweets During the } 2018 \\
\text { Osaka North Earthquake in Japan - A } \\
\text { Brief Report }\end{array}$ & Japon & Conference & 2019 & Earthquake & Japon \\
\hline 4 & $\begin{array}{l}\text { Analyzing the effect of earthquakes on } \\
\text { OpenStreetMap contribution patterns } \\
\text { and tweeting activities }\end{array}$ & $\begin{array}{l}\text { Ahmed } \\
\text { Ahmouda }\end{array}$ & Nepal & 2018 & Earthquake & Nepal \\
\hline 5 & $\begin{array}{l}\text { Characterizing information } \\
\text { propagation patterns in emergencies: } \\
\text { A case study with Yiliang Earthquake }\end{array}$ & Lifang Li & Original & 2018 & Earthquake & China \\
\hline 6 & $\begin{array}{l}\text { Resource mapping during a natural } \\
\text { disaster: A case study on the } 2015 \\
\text { Nepal earthquake }\end{array}$ & $\begin{array}{l}\text { Moumita } \\
\text { Basu }\end{array}$ & Original & 2017 & Earthquake & Nepal \\
\hline 7 & $\begin{array}{c}\text { Medical Requirements During a } \\
\text { Natural Disaster: A Case Study on } \\
\text { WhatsApp Chats Among Medical } \\
\text { Personnel During the } 2015 \text { Nepal } \\
\text { Earthquake }\end{array}$ & $\begin{array}{l}\text { Moumita } \\
\text { Basu }\end{array}$ & $\begin{array}{l}\text { Short } \\
\text { report }\end{array}$ & 2017 & Earthquake & Nepal \\
\hline 8 & $\begin{array}{l}\text { Automatic Identification and Ranking } \\
\text { of Emergency Aids in Social Media } \\
\text { Macro Community }\end{array}$ & $\begin{array}{l}\text { Bhaskar } \\
\text { Gautam }\end{array}$ & Conference & 2017 & Earthquake & Nepal \\
\hline 9 & $\begin{array}{l}\text { Social media during multi-hazard } \\
\text { disasters: lessons from the Kaikoura } \\
\text { earthquake } 2016\end{array}$ & $\begin{array}{l}\text { Briony } \\
\text { Gray }\end{array}$ & Original & 2017 & Earthquake & News land \\
\hline 10 & $\begin{array}{l}\text { Corpus Analysis of Earthquake Related } \\
\text { Tweets through Topic Modelling }\end{array}$ & $\begin{array}{l}\text { Lany L. } \\
\text { Maceda }\end{array}$ & Original & 2017 & Earthquake & Philipine \\
\hline 11 & $\begin{array}{l}\text { Social media and disasters: A new } \\
\text { conceptual framework }\end{array}$ & $\begin{array}{l}\text { Briony } \\
\text { Gray }\end{array}$ & Conference & 2016 & Earthquake & Nepal \\
\hline 12 & $\begin{array}{c}\text { Functions of and communication } \\
\text { behavior on twitter after the } 2015 \\
\text { Nepal earthquake }\end{array}$ & $\begin{array}{l}\text { Bryan } \\
\text { James C. } \\
\text { Malasig }\end{array}$ & Original & 2016 & Earthquake & Nepal \\
\hline 13 & $\begin{array}{l}\text { An overview of Public Concerns during } \\
\text { the Recovery Period after a Major } \\
\text { Earthquake: Nepal Twitter Analysis }\end{array}$ & $\begin{array}{l}\text { Jaziar } \\
\text { Radianti }\end{array}$ & Conference & 2016 & Earthquake & Nepal \\
\hline 14 & $\begin{array}{l}\text { \#Earthquake: Twitter as a Distributed } \\
\text { Sensor System }\end{array}$ & $\begin{array}{l}\text { Andrew } \\
\text { Crooks }\end{array}$ & Original & 2013 & Earthquake & U.S Eastal Coast \\
\hline 15 & $\begin{array}{l}\text { Disaster evacuation for persons with } \\
\text { special needs: A content analysis of } \\
\text { information on YouTube }\end{array}$ & $\begin{array}{l}\text { Jacqueline } \\
\text { K.Owens }\end{array}$ & Original & 2013 & * & * \\
\hline 16 & $\begin{array}{l}\text { Social media use and goals after the } \\
\text { Great East Japan Earthquake }\end{array}$ & Jung, J. Y. & Original & 2012 & Earthquake & Japon \\
\hline 17 & $\begin{array}{l}\text { Classifying Text Messages for the Haiti } \\
\text { Earthquake }\end{array}$ & $\begin{array}{l}\text { Cornelia } \\
\text { Caragea }\end{array}$ & Conference & 2011 & Earthquake & Haiti \\
\hline 18 & $\begin{array}{l}\text { Building an Earthquake Evacuation } \\
\text { Ontology from Twitter }\end{array}$ & $\begin{array}{l}\text { Isabel } \\
\text { Shizu } \\
\text { Miyamae } \\
\text { Iwanaga }\end{array}$ & Conference & 2011 & Earthquake & japon \\
\hline 19 & $\begin{array}{l}\text { The earthquake and tsunami - } \\
\text { observations by Japanese physicians } \\
\text { since the } 11 \text { March catastrophe }\end{array}$ & $\begin{array}{l}\text { Soichiro } \\
\text { Nagamatsu }\end{array}$ & Original & 2011 & $\begin{array}{l}\text { Earthquake - } \\
\text { tsunami }\end{array}$ & Japon \\
\hline
\end{tabular}

In the event of an earthquake, a matter of concern is the rescue of people who could not save their lives for any reason during the earthquake. The findings demonstrated that the people who were able to make a living try to help the affected ones by using social media, such as Twitter and appropriate hashtags. Moreover, organizations can use the messages sent on social media to identify the resources needed by people in the affected areas. People also helped the relevant authorities to identify the resources they needed by sending messages, such as "Food and medicine will run out by tomorrow."

The main information category consisted of three main themes: incident information, warning, and health-related topics. The findings suggested that in the early hours after the earthquake, the most common use of social media was the dissemination of information about how the earthquake occurred, the amount of possible damage, the health of people, and necessary warnings to people about the dangers that threaten their lives. It is about informing about medical procedures and centers that provide relief and medical services, as well as inquiring about those who lost their lives or were missed. In this regard, Twitter was the most used social media. The use of appropriate hashtags for information plays a major role in information dissemination after the earthquake.

The most common type of disseminated information was on the type and extent of damage that occurred in the first $24 \mathrm{~h}$ after the earthquake since people use social media as a source of information to reduce their anxiety about the 


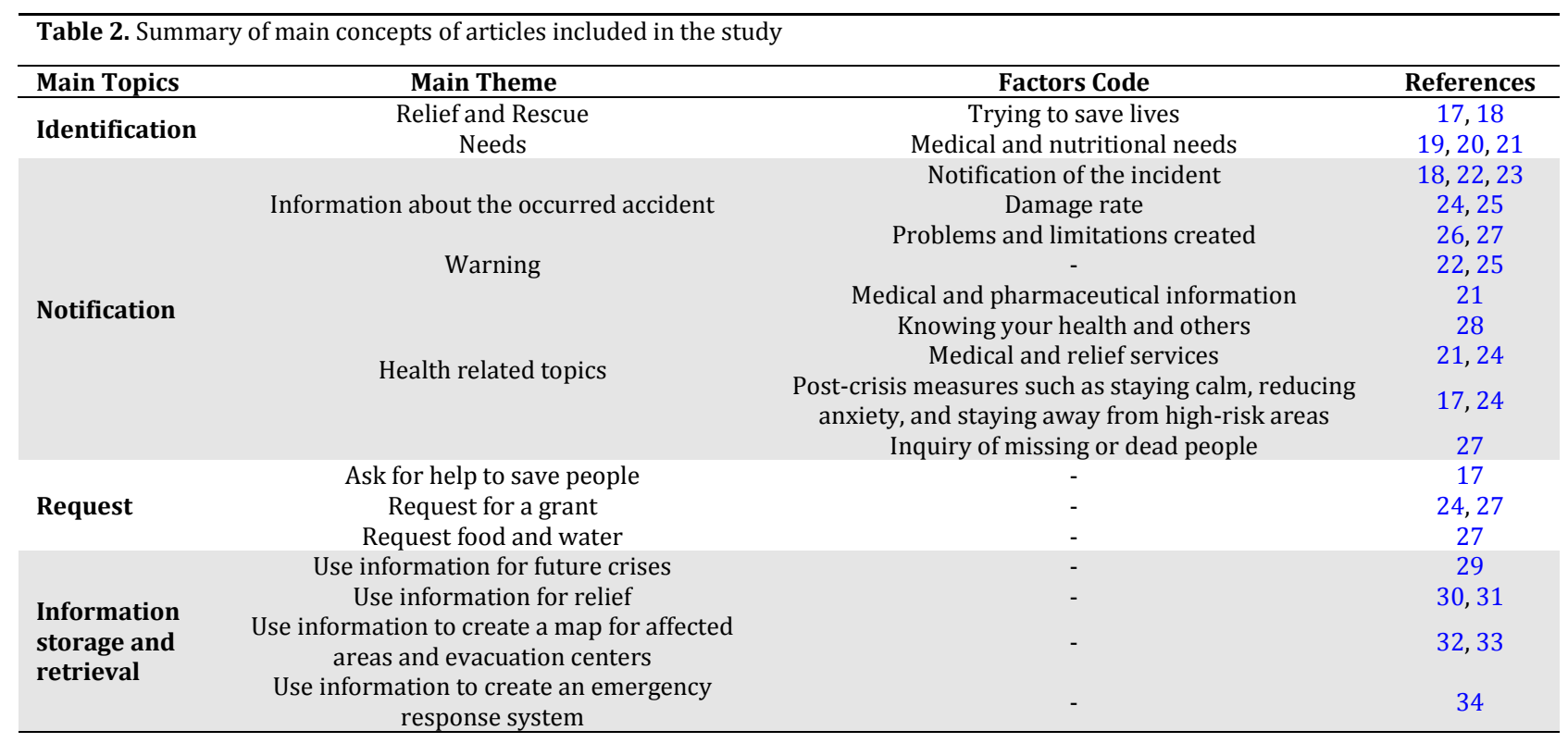

information that is lost during a disaster.

Nonetheless, in the hours after the earthquake (up to $72 \mathrm{~h}$ ), the release of information is based on the provision of relief goods or services. After $72 \mathrm{~h}$ (when communication is established), the information is transmitted more slowly. Finally, in the next stages of information (4-7 months after the earthquake), information about medical, treatment, and financial assistance will be published. It is worth noting that in times of rescue, users mostly re-send other people's posts.

The main category of requests included the three main themes of requesting help to save people, financial assistance, as well as medical items, food, and water. After the earthquake, rescuing people trapped under the rubble is a matter of concern for the survivors of the disaster. In this regard, messages were posted and reposted by people on social media, including Twitter, asking for help to search for people and save their lives. In addition, in the days following the earthquake, messages were sent asking for financial resources, as well as medical items and food, and tweets containing messages asking for action, searching for people, and asking those at the top for help.

The main category of data storage and retrieval consisted of four main themes. The findings illustrated that the information in messages posted by people after such events as earthquakes can be used for future crises and relief. Moreover, it is possible to prepare a map of the affected areas to help evacuate people from the damaged centers and buildings using the available information and tracking where these messages have been published on social media. Furthermore, the stored information can be used for the development of an emergency response system in case of earthquakes or subsequent crises.

\section{Discussion}

This systematic review indicated that social media in disaster relief is a hot research topic in recent years. The roles played by social media in earthquakes can be examined in four main areas: identification, information, requests, as well as the storage and retrieval of information. Based on the findings of related studies, one of the crucial roles of social media in the event of disasters and accidents is the identification and rescue of injured and missing people. In this regard, Henríquez-Coronel et al. stated that after an earthquake, tweets containing messages suggesting identification measures to search for individuals and ask for help were at the top of the messages (17). In the same context, Gray et al. assessed the role of social media during the Nepal earthquake and reported that the hashtag \#rescue was extensively used to communicate and try to rescue injured and missing people (18).

Furthermore, another role of social media in the discussion of identification has been the recognition of the medical and nutritional needs of individuals. In this regard, Basu examined the WhatsApp messenger during the Nepal earthquake and demonstrated that the most common use of WhatsApp was the identification of the needs of various resources and delays in sending these resources $(19,20)$. Along the same lines, Nagamatsu reported observations by Japanese physicians from the first month after the 2011 earthquake. The results of the mentioned study indicated that they used new technologies, such as email lists, and social media, such as Twitter, to send messages such as "water, food, and "The drug will run out by 
tomorrow,".

Another role identified for post-crisis social media in studies belonged to information. One of the most useful information is related to the incident, its severity, the amount of initial damage caused by the earthquake, and the subsequent problems or limitations. In this regard, the results of a study conducted by Gray et al. pointed out that the hashtags \#earthquake and \#Tsunami have been widely used to inform the primary media about the incident. Moreover, in general, the use of the hashtag \#government means political unrest. Nonetheless, in the time of disasters, it refers to the expansion of governmental information in the event of an earthquake, and this hashtag was used to raise awareness in the security and status assessment group $(22,18)$.

In the same context, the results of a study performed by Yamada et al. suggested that the proper use of appropriate hashtags in tweets is beneficial for anyone who wants to follow disaster information in a particular area (23). In their study, Li et al. noted that damage information was the most commonly used dissemination of information in the $24 \mathrm{~h}$ after the earthquake (24). In a similar vein, Maceda et al. reviewed and analyzed Filipino tweets about the earthquake and found that most tweets were about the event, the feeling of the earthquake, the effects of the earthquake, the affected places, and the magnitude of the earthquake. Moreover, the main topics of the messages were related to the magnitude, feeling of the earthquake, and the effects of the earthquake (25).

Malasig and Quinto also examined tweets related to the 2015 Nepal earthquake three days after the quake. They concluded that most of the concepts derived from users' communication behavior in the face of problems and constraints. In their study, Radianti et al. assessed Twitter messages in the Nepal earthquake that contained messages of public concern about the state of the country. The results of the stated study suggested that one of the most prominent issues in people's messages was problems with providing services to victims and airport problems. In this country, there were health problems and rumors (27).

Furthermore, in the field of information, another role of social media was related to warnings. After reviewing Twitter messages, Maceda et al. concluded that information alert was one of the features of social media used by people and governments after the earthquake (25). In the same context, in their study, Gary et al found that the use of the hashtag \#HMCS Vancouver referred to the events that HMCS Vancouver helped with crisis management strategies in local areas. In fact, this hashtag indicates warnings through news channels and media (22).

Finally, another role of social media was the provision of information on health-related topics.
These roles include information about medical and pharmaceutical issues, one's own health and that of others, medical and relief services, post-crisis measures, such as keeping calm, reducing anxiety, and staying away from high-risk areas, as well as inquiring about missing or dying people. Health and wellness are among the most important issues to consider during and after an earthquake in an area. The devotion of assiduous attention to the health of earthquake survivors, relief and medical measures, as well as helping them to stay calm, are some of the measures that can reduce the subsequent problems.

In a survey of Japanese students on the role of social media during an earthquake, they cited Facebook and Twitter as the most common source of information about their health and sharing their public opinion (28). It also examined postearthquake Twitter messages in China in the postearthquake hours (up to 72 hours) by information dissemination based on information about the delivery of relief goods or services. Moreover, the findings showed that people used social media as a source of information to reduce their anxiety about the information that is lost during a disaster (24).

Furthermore, after reviewing and analyzing the messages posted on social media after the earthquake in Mexico, the authorities' recommenddations regarding immediate measures in the early moments of the crisis, such as keeping calm, not using landlines, and staying away from high-risk areas, were conveyed to people via Twitter (17). On the other hand, the findings of the study by Nagamatsu revealed that information about the intensive care unit activities of hospitals, hemodialysis capacity, and mechanical fans in the first $48 \mathrm{~h}$ after the earthquake was provided to the authorities through the website of the Japan Intensive Care Association using Google Map.

In addition, resources and facilities regarding medical and pharmaceutical services, as well as patient transfer based on information obtained from social media, were evaluated(21). According to the aforementioned issues, social media can play a crucial and diverse role in the field of information. It can increase the accuracy of decisions, prevent secondary crises, minimize the presence of nonoperational people in the affected area, and ultimately leads to a marked increase in the accuracy and speed of the measures taken by the rescue forces.

In terms of requests, the research findings showed that most of the requests were related to asking for help to save people, financial help, as well as food and water. The experience of numerous earthquakes around the world has demonstrated that after an earthquake, the request for help to save lives increases due to the caused damages. Moreover, the majority of people and governments need financial assistance due to the severity of the damage. 
In addition, due to the inflicted damages and the lack of resources, the demand for food resources, especially water, has been very high. The results of the analysis of messages posted on social media to help the victims of the earthquake in Nepal showed that one of the most common messages sent to people was the request for financial aid (financial support) and water (27). Another study on the aftermath of the Mexican earthquake and the role of social media reported that most messages in the early hours after the disaster revolved around asking for resources and helping search for people (17). It indicates that social media can be used as a suitable capacity in the field of collecting requests in the affected area to prioritize the deployment of teams and sending shipments with the least possible error.

Another issue that emerged from the findings of the current study was the role of social media in the storage and retrieval of information. In this regard, the information obtained from the messages posted on social media after a disaster, such as an earthquake, can be used for subsequent crises, relief, mapping the affected areas and evacuation centers, and the development of an emergency response system. In their study, Croocks et al. demonstrated that the social media information (Twitter) stored in a system, such as the website of the US Geological Survey, can be used in times of crisis and relief for future events (29). Caragea et al. referred to the creation of a reusable information technology infrastructure called advanced messaging. The components of this infrastructure include: 1) an iPhone application, 2) a Twitter crawler component, 3) machine translation, and 4) automatic message classification (34). In another study, it was found that the usability of the search method in the Twitter social media can help the development of ontology about evacuation centers which will help to quickly evacuate people from the centers (33).

Other studies have pointed to the role of this information in rescuing people (35). In a study, a service and a mobile application mediated a tool, such as citizen messages, through the Twitter server to retrieve messages from citizens living in earthquake-stricken areas to be stored and processed in a geographic database using SQL, and it accelerated relief (30). Moreover, in a study performed by Gautam and Basaua, vector models were used to process text and statistics in order to categorize the information contained on Twitter in order to retrieve information and assist in efforts made to rescue and save lives (31). Social aspects in terms of retention of recorded information, the ability to transfer data to other databases for data analysis, and optimal use, such as drawing different maps (affected areas and emergency accommodation.) with proper planning can maximize the quality of earthquake relief.

\section{Conclusion}

Regarding the importance of social media and its crucial role in critical situations, especially earthquakes, the present study indicated that social media can serve as a bridge to receive and disseminate information between victims and others or as a tool to be used in earthquake management due to the different capacities of social media, such as the possibility of access to information, producing new content, and influencing existing content. Based on the available literature, these roles can be assigned to four main sections, including identification, notification, requests, as well as storage and retrieval of information. Successful experiences of using social media in earthquakes in Haiti, Mexico, China, and Nepal highlighted the importance of social media and its role in crisis situations, especially earthquakes. Consequently, social media as one of the powerful tools in crisis management should receive more assiduous attention.

\section{Footnotes}

Conflicts of Interest: The author(s) declared no potential conflicts of interest with respect to the research, authorship, and/or publication of this article.

Funding/Support: The author(s) received no financial support for the research, authorship, and/or publication of this article

Ethical considerations: Ethical approval was granted by the IRAN National Committee for Ethics in Biomedical Research (IR.KMU.REC.1398.107).

\section{References}

1. Tim Y, Pan SL, Ractham P, Kaewkitipong L. Digitally enabled disaster response: the emergence of social media as boundary objects in a flooding disaster. Inform Syst J. 2017;27(2):197-232. doi: 10.1111/isj.12114.

2. Schultz F, Utz S, Göritz A. Is the medium the message? Perceptions of and reactions to crisis communication via twitter, blogs and traditional media. Public Relat Rev. 2011;37(1):20-7. doi: 10.1016/j.pubrev.2010.12.001.

3. Wright DK, Hinson MD. An updated look at the impact of social media on public relations practice. Public Relat J. 2009;3(2):1-27.

4. Lindsay BR. Social media and disasters: current uses, future options, and policy considerations. Washington, D.C: Congressional Research Service; 2011.

5. Rodríguez H, Quarantelli EL, Dynes RR, Tierney KJ. Businesses and disasters: vulnerability, impacts, and recovery. Handbook of disaster research. New York: Springer; 2007. doi: 10.1007/978-0-387-32353-4_16.

6. Huang CM, Chan E, Hyder AA. Web 2.0 and internet social networking: a new tool for disaster management?-lessons from Taiwan. BMC Med Inform Decis Mak. 2010;10(1):57. doi: 10.1186/1472-6947-10-57. [PubMed: 20925944].

7. Lu Y, Yang D. Information exchange in virtual communities under extreme disaster conditions. Decis Supp Syst. 2011;50(2):529-38. doi: 10.1016/j.dss.2010.11.011.

8. Westerman D, Spence PR, Van Der Heide B. Social media as 
information source: Recency of updates and credibility of information. J Comput Med Communic. 2014;19(2):171-83. doi: $10.1111 /$ jcc4.12041.

9. Shklovski I, Palen L, Sutton J. Finding community through information and communication technology in disaster response. Proceedings of the 2008 ACM conference on Computer supported cooperative work, California, USA; 2008. P. 127-36. doi: 10.1145/1460563.1460584.

10. Haddow GD, Haddow KS. Disaster communications in a changing media world. Oxford: Butterworth-Heinemann; 2013.

11. Wentz B, Lazar J, Stein M, Gbenro O, Holandez E, Ramsey A. Danger, danger! Evaluating the accessibility of Web-based emergency alert sign-ups in the northeastern United States. Government Inform Quart. 2014;31(3):488-97. doi: 10.1016/j.giq.2014.02.010.

12. Fothergill A, Maestas EG, Darlington JD. Race, ethnicity and disasters in the United States: a review of the literature. Disasters. 1999;23(2):156-73. doi: 10.1111/1467-7717.00111. [PubMed: 10379098].

13. Mendoza M, Poblete B, Castillo C. Twitter under crisis: can we trust what we RT? Proceedings of the first workshop on social media analytics, New York, USA; 2010. P. 71-9. doi: 10.1145/1964858.1964869.

14. Laituri M, Kodrich K. On line disaster response community: People as sensors of high magnitude disasters using internet GIS. Sensors. 2008;8(5):3037-55. doi: 10.3390/s8053037. [PubMed: 27879864].

15. Cho SE, Jung K, Park HW. Social media use during Japan's 2011 earthquake: how Twitter transforms the locus of crisis communication. Med Int Aust. 2013;149(1):28-40. doi: 10.1177/1329878X1314900105.

16. Sakurai M, Thapa D. Building resilience through effective disaster management: an information ecology perspective. Int J Inform Syst Crisis Resp Manag. 2017;9(1):11-26. doi: 10.4018/IJISCRAM.2017010102.

17. Henríquez-Coronel P, García JG, Herrera-Tapia J. Management of natural disasters based on twitter analytics. 2017 Mexico earthquake. International Conference on Information Technology \& Systems, La Libertad, Ecuador; 2019. P. 3-12. doi: 10.1007/978-3-030-11890-7_1.

18. Malasig BJ, Quinto EJ. Functions of and communication behavior on twitter after the 2015 Nepal earthquake. Malaysian J Communic. 2016;32(1):140-57. doi: 10.17576/ JKMJC-2016-3201-07.

19. Radianti J, Hiltz SR, Labaka L. An overview of public concerns during the recovery period after a major earthquake: Nepal twitter analysis. 49th Hawaii International Conference on System Sciences (HICSS), Koloa, HI, USA; 2016. P. 136-45. doi: 10.1109/HICSS.2016.25.

20. Li L, Zhang Q, Tian J, Wang H. Characterizing information propagation patterns in emergencies: a case study with Yiliang Earthquake. Int J Inform Manag. 2018;38(1):34-41. doi: 10.1016/j.ijinfomgt.2017.08.008.

21. Maceda LL, Llovido JL, Palaoag TD. Corpus analysis of earthquake related tweets through topic modelling. Int $J$ Machine Learn Comput. 2017;7(6):194-7. doi: 10.18178/ ijmlc.2017.7.6.645.
22. Basu M, Ghosh S, Jana A, Bandyopadhyay S, Singh R. Resource mapping during a natural disaster: a case study on the 2015 Nepal earthquake. Int J Disas Risk Reduct. 2017;24:24-31. doi: 10.1016/j.ijdrr.2017.05.020.

23. Basu M, Ghosh S, Jana A, Bandyopadhyay S, Singh R. Medical requirements during a natural disaster: a case study on WhatsApp chats among medical personnel during the 2015 Nepal earthquake. Disas Med Public Health Prep. 2017; 11(6):652-5. doi: 10.1017/dmp.2017.8. [PubMed: 28606208].

24. Nagamatsu S, Maekawa T, Ujike Y, Hashimoto S, Fuke N. The earthquake and tsunami-observations by Japanese physicians since the 11 March catastrophe. Crit Care. 2011;15(3):167. doi: 10.1186/cc10261. [PubMed: 21722338].

25. Crooks A, Croitoru A, Stefanidis A, Radzikowski J. \#Earthquake: Twitter as a distributed sensor system. Transact GIS. 2013;17(1):124-47. doi: 10.1111/j.14679671.2012.01359.x.

26. Di Felice P, Iessi M. A Citizen-sensing-based digital service for the analysis of on-site post-earthquake messages. ISPRS Int J Geo Inform. 2019;8(3):136. doi: 10.3390/ijgi8030136.

27. Ahmouda A, Hochmair HH, Cvetojevic S. Analyzing the effect of earthquakes on open Street Map contribution patterns and tweeting activities. Geo Spatial Inform Sci. 2018;21(3):195-212. doi: $10.1080 / 10095020.2018 .1498666$.

28. Caragea C, McNeese N, Jaiswal A, Traylor G, Kim HW, Mitra P, et al. Classifying text messages for the Haiti earthquake. Proceedings of the 8th international conference on information systems for crisis response and management, Lisbon, Portugal; 2011. doi: 10.1.1.370.6804.

29. Gautam B, Basaua A. Automatic identification and ranking of emergency aids in social media macro community. Bangalore, India: Arxiv Preprint Arxiv; 2018.

30. Gray B, Weal M, Martin D. Social media and disasters: a new conceptual framework. Proceedings of the ISCRAM 2016 Conference, Brazil; 2016.

31. Gray B, Weal MJ, Martin D. Social media during multi-hazard disasters: Lessons from the Kaikoura Earthquake. Int J Safety Security Eng. 2017;7(3):313-23 2016. doi: 10.2495/SAFEV7-N3-313-323.

32. Yamada S, Utsu K, Uchida O. An analysis of tweets during the 2018 Osaka North earthquake in Japan-A brief report. 5th International Conference on Information and Communication Technologies for Disaster Management, Sendai, Japan; 2018. P. 1-5. doi: 10.1109/ICT-DM.2018.8636393.

33. Iwanaga IS, Nguyen TM, Kawamura T, Nakagawa H, Tahara Y Ohsuga A. Building an earthquake evacuation ontology from twitter. 2011 IEEE International Conference on Granular Computing, Kaohsiung, Taiwan; 2011. doi: 10.1109/ GRC.2011.6122613.

34. Latonero M, Shklovski I. Emergency management, Twitter, and social media evangelism. Int J Inform Syst Crisis Resp Manag. 2011;3(4):1-6. doi: 10.4018/jiscrm.2011100101.

35. Rezaei F, Maracy MR, Yarmohammadian MH, Sheikhbardsiri $\mathrm{H}$. Hospitals preparedness using WHO guideline: A systematic review and meta-analysis. Hong Kong Journal of Emergency Medicine. 2018;25(4):211-222. doi: 10.1177/ 1024907918760123 